\title{
Canadian Association of
}

\section{Gastroenterology: Thirty years back and a few years forward to the year 2000}

$\mathrm{T}$ HE CANADIAN ASSOCIATION OF GASTROENTEROLOGY HAS A rich and detailed history of enthusiasm and dedication among its founding members, its executive, and its membership. Dr IT Beck has thoughtfully and thoroughly prepared a history of the Association (see page 345). We owe him a debt of gratitude for this masterpiece.

Initially the focus of the Association was on education. Initiated by educators, the Association gradually grew to include an Annual Meeting, a one-day course, regional meetings, bids for World Congresses and, more recently, a successful initiation of an extensive course for Gl Training Fellows. That focus of education has been essential for the success of the Association, providing input to the Canadian Society for Clinical Investigation, the Royal College of Physicians and Surgeons, and other subspecialty groups within Canada.

As the mandate for education evolved, it was recognized that the educational mandate needed to be directed towards involving community physicians as well as trainees, basic scientists with an interest in gastroenterology, pediatricians, surgeons/ pathologists, members of the pharmaceutical industry, in fact any professional, and radiologists with an interest in gastroenterology. The Executive has worked hard to broaden its representation to include individuals with a wide range of interests and activities. Certainly there continues to be a need to provide for a more democratic method of representing the wishes and needs of the rank and file, but this is our Association and it is our responsibility to work hard to improve and to make it representative of our wishes. Indeed, this is 'our Association' and the 'them' becomes 'us' simply by the process of participation.

But education is not enough, and the Association has become increasingly involved in the establishment of funds for the research training of gastroenterology fellows and students. Through the generous sponsorship of Glaxo Canada, Merck Frosst Canada, Janssen Canada and the Canadian Foundation for Ileitis and Colitis, numerous scholarships and awards have been established. In this way, gastroenterologists of the future can strengthen their training by way of an emphasis on scholarly activities and research. With the recognition that the clinician investigator on gastroenterology (as well as in other subspecialties) is an endangered species, the Association has begun discussions with the view to establishing a Research Foundation from which funds for research projects might be obtained in the future. The role of the Research Committee of the Association has been important in establishing a dialogue between the
Education and Program Committees as well as with the scientists themselves, and this blending of education and research will continue to be an important future development.

What then are some of the new challenges of the Association? Certainly the efforts to make this Association from shore to shore and from university to community is admirable. The close dialogue with other professional associations with a specified interest in gastroenterology is important, and the already good relationship with the Canadian Association for the Study of the Liver needs to be maintained and strengthened.

Perhaps the Association needs to become more confident in itself and in its members. Now incentives need to be viewed from the perspective of potential success, rather than potential failure. The Canadian Journal of Gastroenterology is five years strong, has a wide circulation, and is respected internationally. It has always been a voice for the Association, an unofficial one at that, but because of its very independent status, the Journal has addressed some of the thorny issues which perhaps the Association might be uncomfortable dealing with. The relationship between the Association and an independent Journal needs to be clarified.

Perhaps the most important area for the future lies in the area of assisting in the establishment of programs of medical quality improvement in gastroenterology, assisting in the development of outcome analyses, and the development of much needed Canadian guidelines for endoscopic cost containment. The Association needs to take a much stronger role in the area of endoscopy, taking leadership in the areas of interaction with governments on such thorny issues as training, certification and EQI (Endoscopy Quality Improvement). The skill and expertise of the members of the Association need to be directed and focused on issues of optimal patient investigation and treatment. The first Consensus Conference on Gastroesophageal Reflux Disease was an important initiative, and this needs to be followed by other consensus conferences.

The Association is strong and like an enthusiastic youth, or the rebellious teenager, and like any normal family, there have been ups and downs. But these have made the Association stronger, have brought the members closer together, and have provided, in fact, the very strength from which we move forward. And forward we look to the maturing and the wisdom of the 2000s. 


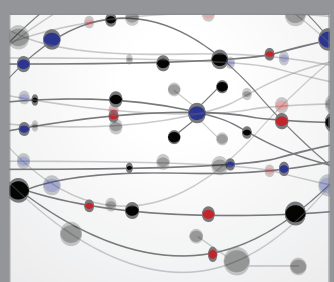

The Scientific World Journal
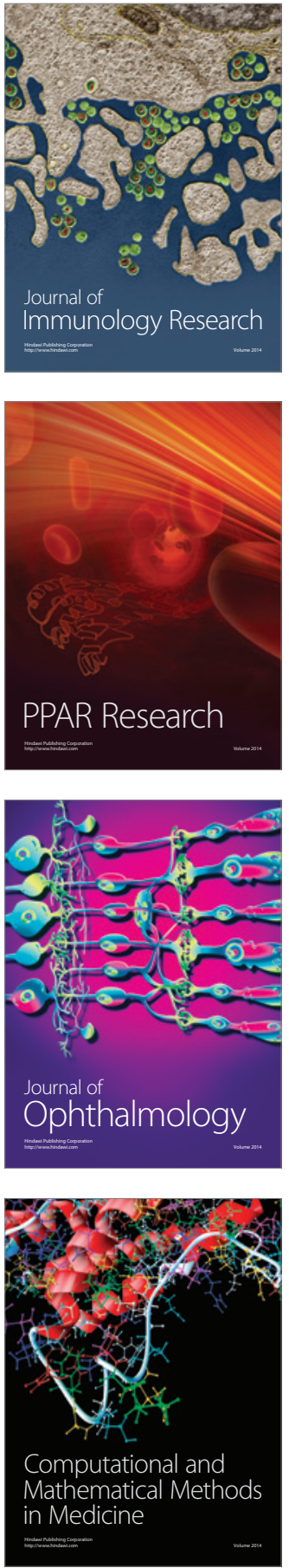

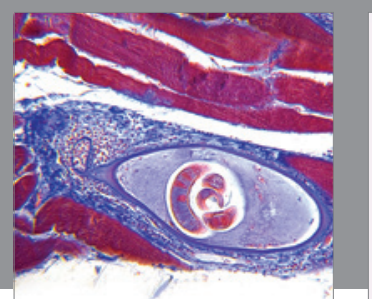

Gastroenterology Research and Practice

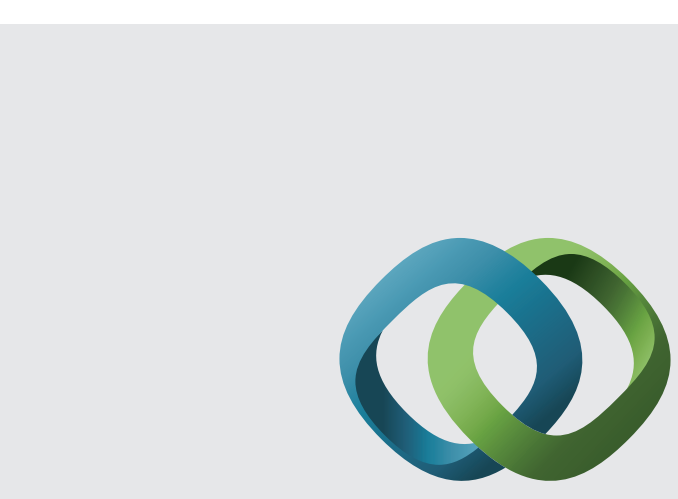

\section{Hindawi}

Submit your manuscripts at

http://www.hindawi.com
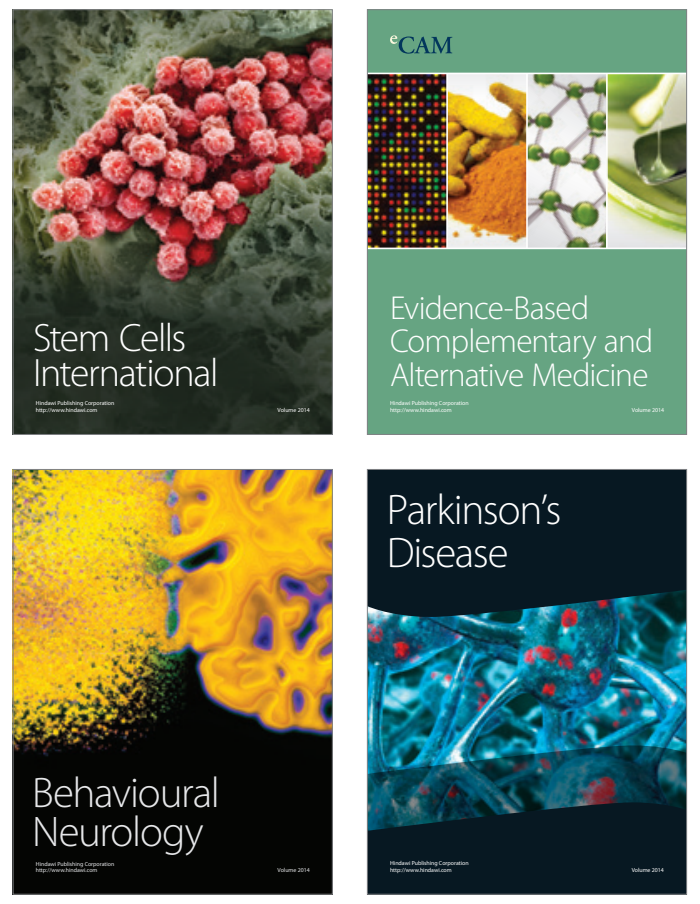
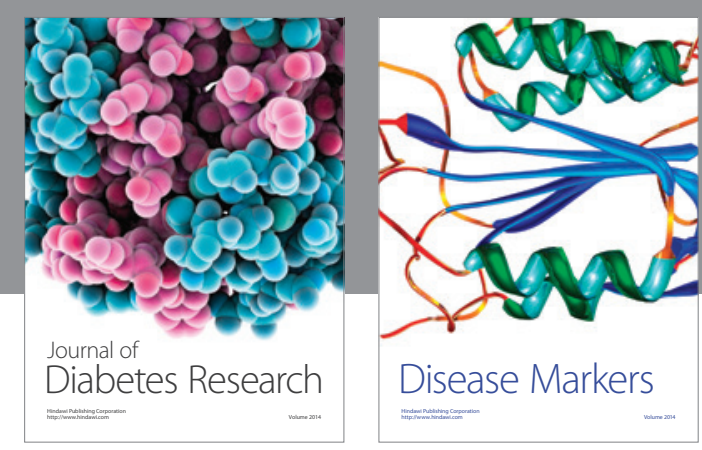

Disease Markers
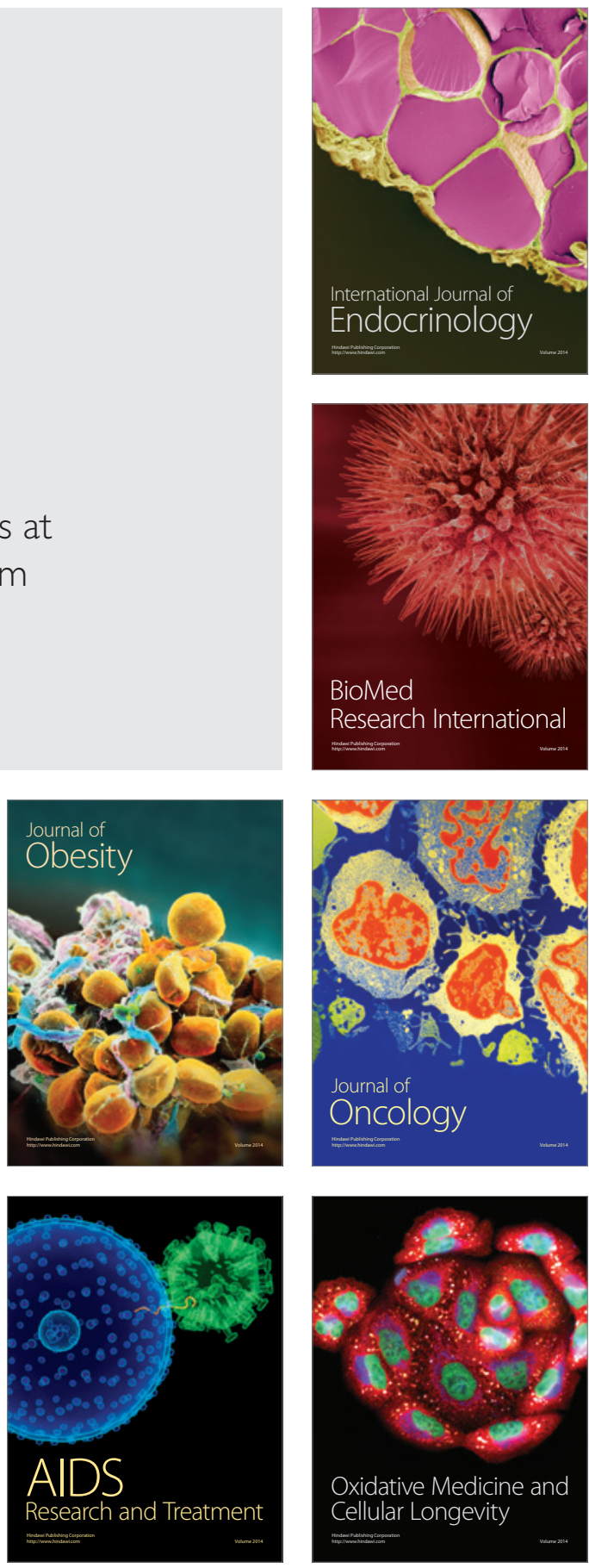